\title{
CEREBRAL PALSY IN RELATION TO MATERNAL HEALTH
} Kisa Fatima $^{I}$ \& Maria Altaf ${ }^{2}$

1. Dow Institute Of Medical Technology, DUHS.

2. Fatima Jinnah Dental College.

Corresponding author: canceria3791@gmail.com

\begin{abstract}
Cerebral palsy (CP) is neurological disorder which effect motor and sensory neurons the effected individual may suffer ophthalmic problems, impaired speech, movements and posture mental and physical abnormalities as well. The study design was observational prospective, done on the population consists of 65 mothers having their child with $\mathrm{CP}$, and children with other physical and mental disabilities were completely excluded. The data was collected at Dow Institute of Physical Medicine and Rehabilitation (IPM\&R), DUHS.Prenatal causes (placenta previa, hypertension, diabetes, and seizures) accounted for majority of CP conditions. 21.5\% mothers were found with gestational diabetes, $56.9 \%$ with hypertension, $16.9 \%$ with seizures and $20.0 \%$ with placenta previa.As it is well observed that Women with pregnancy induced diabetes (gestational diabetes) have a greater chance of having a baby with birth defects including CP. Gestational diabetes puts the fetus at greater risk of $\mathrm{CP}$ while women with hypertension are also most likely to have a child with CP.
\end{abstract}

\section{KEYWORDS}

CP: Cerebral palsy, OR: odds ratio

\section{PURPOSE OF STUDY}

To know what Cerebral Palsy is and correlating the causes of CP in relation to maternal health and reducing the risks with prenatal care.

\section{INTRODUCTION}

Originally it was reported in 1861by Little that Cerebral Palsy is a neurological disorder which starts from early age and ends till death which was known as 'cerebral paresis'(Bax, M., 2005)

For the past 40 years, the definition of $\mathrm{CP}$ has been the classic, Bax stated that $\mathrm{CP}$ is a disorder of movements, position due to problem in particular area of brain i.e. cerebrum(Rosenbaum, P. (2006)

Cerebral palsy 'a neurological disorder which effects motor and sensory neurons the effected individuals may suffer from ophthalmic problems, impaired speech, movements and posture mental and physical abnormalities as well'The risk of cerebral palsy seems to be higher in children having problems postnataly including pre-mature birth, and some infections such as: jaundice, epilepsy, and infections involving brain in a very early age (Ashwal, S., 2004)Brain of a child may be effected in pre, peri or postnataly but it is diagnosed after a certain period by observing baby's activities specially parents get worried when baby doesn't response on certain stimulus, or do not perform motor activities in proper age such as, sitting, crawling etc. (Clark, G. D 1998) Diagnosis of CP not only includes laboratory tests but also includes physical examinations, observations, mothers, child and family history (Bryson, C. L., 2003).It was observed that Gestational diabetes was more strongly associated with pregnancyinduced hypertension in women who had less prenatal care $(\mathrm{OR}=4.2$ for eclampsia and $\mathrm{OR}=3.1$ for severe preeclampsia, $\mathrm{p}<0.05$ for both) and among Black women (OR for eclampsia and preeclampsia together $=3.9, \mathrm{p}<0.05$ ). (Murphy DJ, 1995) Pre-eclampsia was associated with a reduced risk of cerebral palsy $(0.4$ [0.2-0.9]),( Parham, P. (2004)

Pregnancy-induced hypertension and gestational diabetes are also relatively common and affects some percent of pregnancies, resulting in many complications that primarily affect the fetus, including macrosomia, stillbirth, jaundice, and related pulmonary infections (Williams, M. A.,1999) It was found that the comparison between gestational diabetes and pregnancy-induced hypertension differed among the high and low prenatal care. Gestational diabetes was found with lower risk of pregnancy-induced hypertension among those women who received more prenatal care. While women with low prenatal care has been described as increasing the risk of preeclampsia by 30 percent. (Mostello, D. 2002; Gray, P. H. 1998 ) but some studies says that those mothers who are having Magnesium Sulphate in diagnosed pregnancy induced hypertension are protective against Cerebral Palsy and cognitive impairment.( Schendel, D. E 1996)no association found between prenatal magnesium sulfate exposure and death of an infant, those females who were exposed to magnesium sulfate had less chances of $\mathrm{CP}$ or MR than those not exposed (O'Shea 1999). A 42 day course of dexamethasone was experimented on pregnant mothers which can cause neurological disorder mainly CP.( Rosenbaum, P., 2007).

\section{METHODOLOGY}

The study design was observational prospective, done on the population consists of 65 mothers having their child with $\mathrm{CP}$, and children with other physical and mental disabilities were completely excluded. The data was collected in the period of 3 months at Dow Institute of Physical Medicine and Rehabilitation (IPM\&R), DUHS. A letter was sent to IPM\&R for data collection and after getting permission we started our study, we followed questionnaires and interviewed mothers about the problems they had in their gestational period. Questionnaires consist of mother's bio-data including their socio-economic level, educational level because after this study it was well-observed that mothers who belong to lower class were more prone to deliver child with $\mathrm{CP}$ because of lack of nutrition, education\& prenatal care. Questionnaires also consist of prenatal, peri-natal and post-natal complications but we focused on prenatal. The questions which were highlighted were whether the mother faced pregnancy induced hypertension, gestational diabetes, prenatal seizures and placenta previa.

\section{RESULTS}

This observational prospective study shows that, prenatal causes i.e. placenta previa, hypertension, diabetes and seizures accounted for majority of $\mathrm{CP}$ conditions. $21.5 \%$ mothers were found with gestational diabetes), $56.9 \%$ with hypertension $16.9 \%$ with seizures and $20.0 \%$ with placenta previa.

Graphical representations for the following results are given below: 

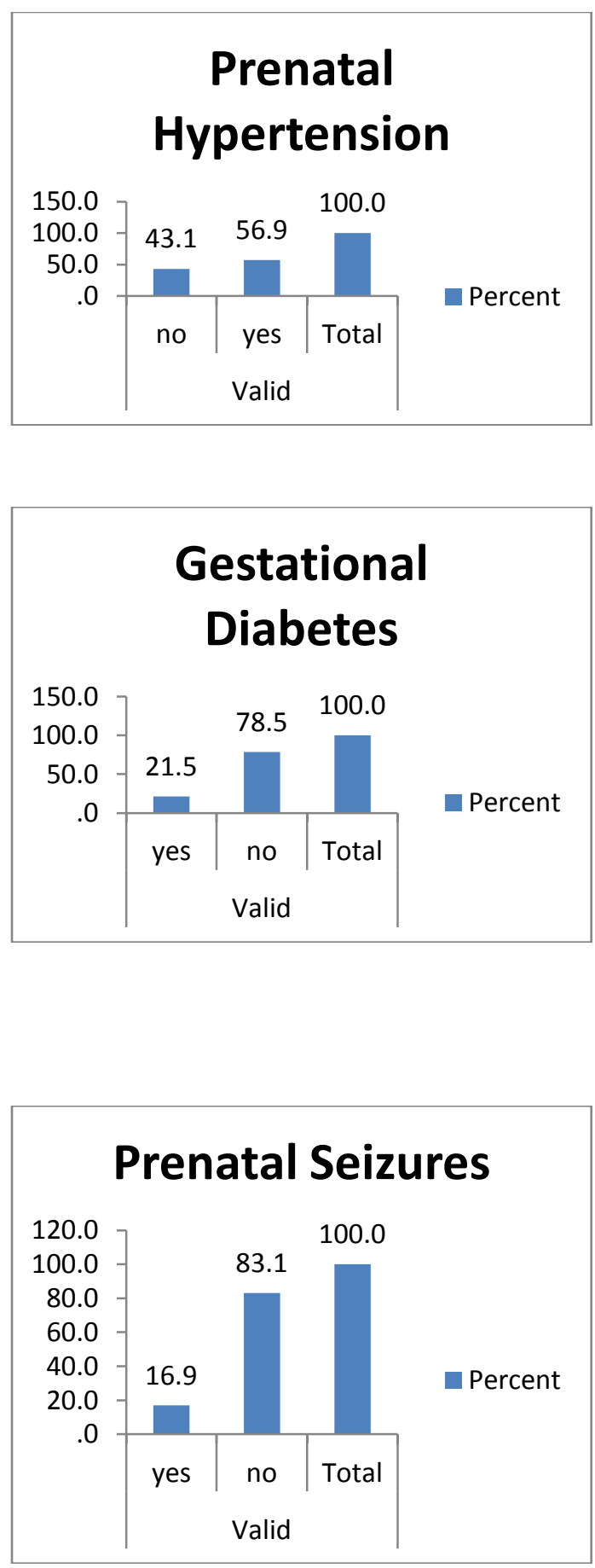

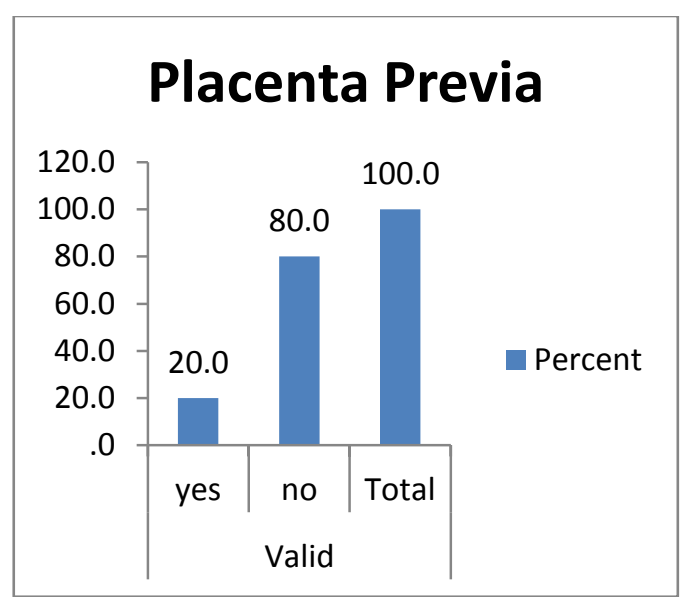

\section{DISCUSSION}

This study was done to know about cerebral palsy and maternal health which causes CP. Cp is known as a bunch of neurological disorders which affects motion, movements, and audio-visual problems which effects fetus during development or infants brain motor disorder of CP is also accompanied by mental state, awareness, comprehension, interaction (Grether, J. K.,1997). Subjects involved in this study were mainly mothers who were having their child with $\mathrm{CP}$ and children with other disabilities were excluded.A single disorder which causes motor dysfunction is not considered as CP. However, patients with neurological disabilities which donot effect movements and postures are also not consider to have CP(Grether, J. K 1997)In this study when mothers were asked about the problems which they faced in their gestational period, the highlighted problems were gestational diabetes, hypertension, prenatal seizures and placenta previa (tables are given in results).infected mothers were associated with increased risk of $\mathrm{CP}$ even in infants if normal birth weight. Maternal infections will also cause low Apgar score, evidences of hypertension, neonatal seizures and birth asphyxia also causes CP (Nelson, K. B., 1985) For evaluating pre-natal and peri-natal antecedents 400 mothers were observed for confirming some causes of $\mathrm{CP}$ in association with mental retardation, seizures, hyperthyroidism, some predicted risk factors were smoking history, gestational diabetes, vaginal bleeding in first trimester, urinary infections, hypertension (Donnelly.JF,1954) Neurological malfunctions due to pregnancy induced hypertension are the most common cause of maternal death from these disorders(Gibbs CE,1968-1973; Tomkinson J, 1976-1978).However,the pathogenesis of these complications, namely eclamptic seizures, coma, visual disturbances and localising neurological defects, remains poorly understood. Mothers were also questioned about their education level that either they were literate or illiterate and the results we get were $38.5 \%$ were literate and $61.5 \%$ were illiterate, their socio economic level, that whether they belong to high, middle or low class so prenatal care can be predicted easily in which $63.1 \%$ belongs to middle class and $36.9 \%$ belongs to low class. There were 65 mothers and the mean of their age was \pm 29.56 with standard deviation of \pm 5 .4, mothers were also questioned about their mode of delivery i.e.; either they deliver their baby at home, hospital with normal delivery, hospital with cesarean.

Graphical Representations for the following results are given below: 


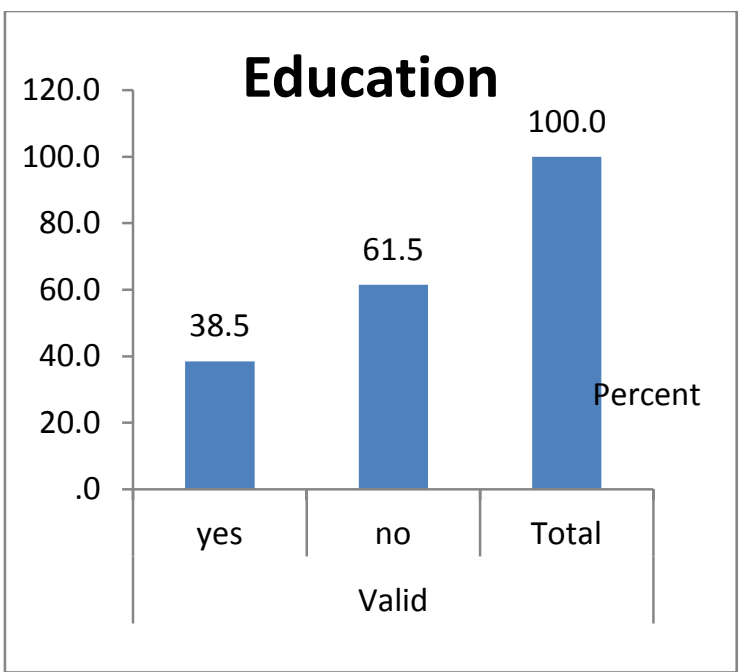

\section{Socioeconomic level}
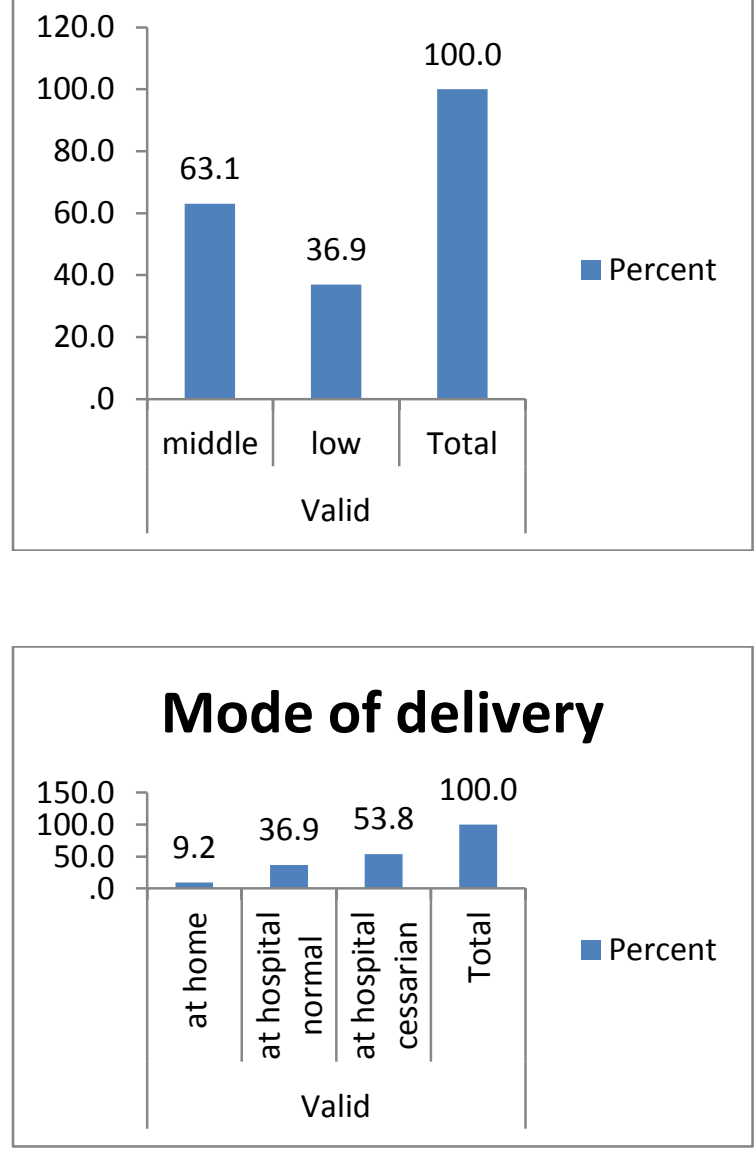

\section{CONCLUSION}

As it is observed that Women with pregnancy induced diabetes (gestational diabetes) have a greater chance of having a baby with birth defects including CP. Gestational diabetes puts the fetus at greater risk of $\mathrm{CP}$ while women with hypertension are also well most likely to have a child with $\mathrm{CP}$. CP is unpreventable but mothers can have a proper prenatal care by controlling diabetes, anemia, hypertension, seizures, and nutritional deficiencies during pregnancy can help prevent some premature births and, as a result, some cases of cerebral palsy. Getting the proper prenatal care may reduce the risks that can lead to some rare causes of $\mathrm{CP}$.

\section{REFRENCES}

1. Bax, M., Goldstein, M., Rosenbaum, P., Leviton, A., Paneth, N., Dan, B., ...\&Damiano, D. (2005). Proposed definition and classification of cerebral palsy, April 2005. Developmental Medicine \& Child Neurology, 47(08), 571-576.

2. Rosenbaum, P. (2006). The Definition and Classification of Cerebral Palsy Are We Any Further Ahead in 2006?. NeoReviews, 7(11), e569-e574.

3. Ashwal, S., Russman, B. S., Blasco, P. A., Miller, G., Sandler, A., Shevell, M., \& Stevenson, R. (2004). Practice Parameter: Diagnostic assessment of the child with cerebral palsy Report of the Quality Standards Subcommittee of the American Academy of Neurology and the Practice Committee of the Child Neurology Society. Neurology, 62(6), 851-863

4. Clark, G. D., M.G. (1998). The cerebral palsy: Causes, consequences and management. Boston: ButterworthHeinemann

5. Bryson, C. L., Ioannou, G. N., Rulyak, S. J., \&Critchlow, C. (2003). Association between gestational diabetes and pregnancy-induced hypertension.American Journal of Epidemiology, 158(12), 1148-1153.

6. Murphy DJ, Sellers S, MacKenzie IZ, Yudkin PL, Johnson AM (1995). Case-control study of antenatal and intrapartum risk factors for cerebral palsy in very preterm singleton babies. Lancet. 1995 Dec 2;346(8988):1449-1454.

7. Parham, P. (2004). NK Cells and Trophoblasts Partners in Pregnancy. The Journal of experimental medicine, 200(8), 951955.

8. Williams, M. A., Farrand, A., Mittendorf, R., Sorensen, T. K., Zingheim, R. W., O'Reilly, G. C.,\&Luthy, D. A. (1999). Maternal second trimester serum tumor necrosis factor- $\alpha$ soluble receptor p55 (sTNFp55) and subsequent risk of preeclampsia. American journal of epidemiology, 149(4), 323329.

9. Mostello, D., Catlin, T. K., Roman, L., Holcomb Jr, W. L., \&Leet, T. (2002). Preeclampsia in the parous woman: Who is at risk?. American journal of obstetrics and gynecology, 187(2), 425-429.

10. Gray, P. H., O’Callaghan, M. J., Mohay, H. A., Burns, Y. R., \& King, J. F. (1998). Maternal hypertension and neurodevelopmental outcome in very preterm infants. Archives of Disease in Childhood-Fetal and Neonatal Edition, 79(2), F88F93.

11. Schendel, D. E., Berg, C. J., Yeargin-Allsopp, M., Boyle, C. A., \& Decoufle, P. (1996). Prenatal magnesium sulfate exposure and the risk for cerebral palsy or mental retardation among very 
low-birth-weight children aged 3 to 5 years.JAMA: the journal of the American Medical Association, 276(22), 1805-1810.

12. O'Shea, T. M., Kothadia, J. M., Klinepeter, K. L., Goldstein, D. J., Jackson, B. G., \& Weaver, R. G. (1999). Randomized placebo-controlled trial of a 42-day tapering course of dexamethasone to reduce the duration of ventilator dependency in very low birth weight infants: outcome of study participants at 1-year adjusted age. Pediatrics, 104(1), 15-21.

13. Rosenbaum, P., Paneth, N., Leviton, A., Goldstein, M., Bax, M., Damiano, D., ...\&Jacobsson, B. (2007). A report: the definition and classification of cerebral palsy April 2006. Dev Med Child NeurolSuppl, 109(suppl 109), 8-14.

14. Grether, J. K., \& Nelson, K. B. (1997). Maternal infection and cerebral palsy in infants of normal birth weight. JAMA: the journal of the American Medical Association, 278(3), 207-211.
15. Nelson, K. B., \&Ellenberg, J. H. (1985). Antecedents of cerebral palsy: I. Univariate analysis of risks. Archives of Pediatrics \& Adolescent Medicine,139(10), 1031.

16. Donnelly JF, Lock FR, Winston-Salem NC (1954) . Causes of death in 533 fatal cases of toxemia of pregnancy. Am J Obstet Gynecol;68:184-9.

17. Gibbs CE, Locke WE. Maternal deaths in Texas, 1968-1973. Am J Obstet Gynacol 1976;126:687-91.

18. Tomkinson J, Turnbull A, Robson G, et al 1976-1978. Report on confidential enquiries into maternal deaths in England and Wales,. London: Her Majesty's Stationery Office, 1978. 